\title{
A Microcontroller-Based Monitoring System for Batch Tea Dryer
}

\author{
Marjan Javanmard \\ Department of Process and Food Engineering \\ Faculty of Engineering \\ University of Putra Malaysia, 43400, Serdang, Malaysia \\ E-mail: marjanjavanmard@hotmail.com \\ K.A. Abbas \\ Department of Food Technology \\ Faculty of Food Science \& Tecnology \\ University of Putra Malaysia, 43300, Serdang, Selangore, Malaysia \\ Tel: 60-3-8946-8534 E-mail: Ali_kassim@hotmail.com \\ Farshad Arvin \\ Department of Computer and Communication System Engineering \\ Faculty of Engineering \\ University of Putra Malaysia, 43400, Serdang, Malaysia \\ E-mail: gs21875@mutiara.upm.edu.my
}

\begin{abstract}
This paper presents an automated tea dryer system based on programmable controller which controls moisture content of the tea leaves and temperature of the chamber in different stages of drying. Several techniques were used for tea drying systems according to the tea genres. The batch tea dryer is designed with 6 to 8 trays. The temperature above the trays is controlled between $50^{\circ} \mathrm{C}$ and $100^{\circ} \mathrm{C}$. Moreover, the moisture content of the tea leaves declined from around $68 \%$ to approximately under $3 \%$. In addition, the temperature of the leaves increased from a little less than $30^{\circ} \mathrm{C}$ to $80^{\circ} \mathrm{C}$. $\mathrm{A}$ microcontroller as the main processor was deployed to process received data from sensors and also it provides control signals. Thus, this system equipped a data logger memory to record data during drying process. The analyses of dryer products shown the feasibility of using propose system for batch tea drying.
\end{abstract}

Keywords: Tea dryer, Batch, Moisture, Microcontroller

\section{Introduction}

In manufacturing of black tea the moisture of the tea (termed dhool) is about $70 \%$ wet bases (W.B.) is decreased to target moisture of $2.5 \%-3 \%$ W.B. in approximately 20 minutes period in order to obtain the best quality of the product (Temple, 2001).

Although in tea production the most energy consuming process is drying, but because tea manufacture is mainly in countries that labor costs are low, automation and monitoring and process control were not an issue in the past. For this reason most factories process control is done manually.

Typical dryer capacity fluctuate from about $100 \mathrm{~kg} / \mathrm{hr}$ to $300 \mathrm{~kg} / \mathrm{hr}$ and the average of fuel consumption is around $45 \mathrm{~kg} / \mathrm{hr}$. Absence of controlling will lead to wastage of energy and moreover to lower throughputs.

Nowadays, producers know the importance of process control which will lead to increasing quality but investing in high technology equipments is not always able to be carried out. Therefore, automation equipment is better to be 
manufactured locally. Tea drying process is used to be concerned with monitoring and detecting the inlet air temperature, outlet air temperature, drying time, air volume and feed teas which differ in their moisture contents and grade.

In tea drying different types of dryers are applied to reduce the moisture content of the wet dhool. The most regular dryer is the fluid bed dryer followed by an endless chain pressure dryer. Even though it has its advantages but it is rarely encountered and cross flow dryer is not normally used because of sensitivity to changes in feed rate. Predictably, this type is highly sensitive to load variation, could similarly be susceptible to changes in hot air temperature and flow rate. Ultimately modifications would affect the process (Temple, 2000).

In tea drying different types of dryers are applied to reduce the moisture content of the wet dhool. The most regular dryer is the fluid bed dryer followed by an endless chain pressure dryer. Even though it has its advantages but it is rarely encountered and cross flow dryer is not normally used because of sensitivity to changes in feed rate. Predictably, this type is highly sensitive to load variation, could similarly be susceptible to changes in hot air temperature and flow rate. Ultimately, modifications would affect the process (Temple, 2000).

The automated controllers are employed to monitor drying process systems. Several monitoring systems are used in industrial companies such as programmable logic controller (PLC). The installing of these systems is very expensive and required a large floor area. In the small-scale systems such as proposed dryer, the automation with PLC is not commercial. Therefore, the low-cost approaches are required to manufacturing the small-scale systems. One of these approaches which is utilized in our system is microcontroller-based hardware. This module is used in proposed dryer as the main processor.

The objective of this work is to design a batch tea dryer with controllers. The proposed tea dryer is designed for effective control of the drying process is implemented with microcontroller.

The variables that were investigated were the objective of drying, model of batch dryer, data logging system and control strategy based on microcontrollers.

\section{Tea Drying Method}

The drying process occurred in a closed chamber where hot air is passed over tea leaves which resulted to heat and mass transfer between air and the drying leaves. Energy is provided by air stream to supply the heat needed for evaporation of moisture from tea, the evaporated moisture is carried away from the tea leaves by air stream (Jayaraman, Gupta, 1995).

The cycle of air drying because of the high moisture content in tea includes three stages, the equilibrium stage which food is heated to reach its drying temperature the constant rate stage that water evaporates from a saturated surface of tea at a proportional rate to moisture content and falling rate period which begins after the moisture content is reached (Canovas, Ma, Barletta, 1997). During the constant rate period, the temperature of the surface of tea becomes equal to wet bulb temperature analogous to air temperature and humidity in similar locations. During the falling rate stage, tea temperature reaches the dry bulb temperature of the air (Mujumdar, Menon, 1995). Values that are established from moisture studies are crucial for understanding how food absorbs and loses moisture (Temple, Boxtel, 2000). In black tea manufacturing the macerated leaf undergoes fermentation which is actually an enzymatic oxidation (Temple, 2001). If the level moisture of the input tea is more, it will require more heat to remove it. The method for measuring the humidity of air at drying temperatures was with a psychrometer (Temple, Boxtel, 1999). Measuring the wet bulb and dry bulb temperature the device modifies the inlet and exhausted air. Inlet air temperature should be above $83^{\circ} \mathrm{C}$ to bestow good quality of dried tea and it should be below $99^{\circ} \mathrm{C}$ to prevent tealeaves from case hardening and burning.

The moisture that is in the air from the drying process is the exhausted temperature, which illustrates drying conditions. The exhaust temperature should be between $49^{\circ} \mathrm{C}$ and $57^{\circ} \mathrm{C}$ depending on the inlet air temperature. It is important to include that if the exhaust temperature is higher the efficiency of the dryer while be lower.

Furthermore, it is understood air acts like a medium in tea drying process. The volume of air required depends on the type of tea. Moreover it is obvious that the leaves thickness can affect the drying process if the leaves are thick they can cause backpressure. Lastly, drying time is important to obtain a stable drying. Long drying damages the tea quality and fast drying can cause the tea to be bitter. Usually tea-drying duration is between 15 and 25 minutes, which is dependent on the quantity of the heat, tea leaf thickness, and certainly on the type of tea.

\section{Dryer Design}

Air which is heated with gas or oil is not used due to the fact that in burning process it may make smoke which will give tea leaves a low quality. A tray or cabinet batch dryer is the simplest type of dryer (Crapiste, Rotstein, 1997).

In this dryer there is a heater device which provides the hot air with approximately 17000 cubic feet per minute (CFM) moreover it will reach the temperature around $94^{\circ} \mathrm{C}$ which is required for the process. This air is sent to the chamber with an air fan. The fan pulls air horizontally between and vertically through the batch dryer trays. Via the damper exhausted air can be recycled into the chamber again. The designed dryer has stainless steel trays, which have punched holes, so the heated air could pass though them. Each batch drier is designed to carry 6 to 8 trays (Javanmard, Arvin, 
2008). The spread thickness depends on the type of tea for thin leaves, it could be feed to about $5 \mathrm{~cm}$ but for the thick leaves, it is better to use a liner layer for about $4 \mathrm{~cm}$. However, if the tea is placed in layers with approximately $2 \mathrm{~cm}$ to $5 \mathrm{~cm}$ it would be possible to detect drying conditions in a superior way.

Moreover, in this design there were a change in the position of the fan and the heater system. As it is shown in Fig.1 originally the heater is put after the fan. Reversing the position of fan and heater will affect the drying rate. Thus, this change was indicated in Fig.2.

As shown in Fig.2 (a) air is first heated and then sent into the fan. The air in this condition will have less turbulence so the fan can send the air with a higher rate in velocity, if so the evaporation of water from the tea will increase. In contrast, the high heat will damage the fan so technically it is not so good even though the rate of drying will increase. In the dryer proposed which is shown in Fig. 2 (b) the position of the fan and the heater is changed so in this case the ambient air will first pass through the fan so their would not be any damage and then it will be heated. It is for certain the drying rate will decrease but also the energy cost and damage of the fan will decrease will it too. So another important aim of the dryer which is being economic will be established.

In addition, there is another fan inserted in the dryer. The purpose of putting another fan is to get higher efficiency. Due to getting feedback's from the system continuously, if the threshold of the chamber temperature suddenly increases from the predicted temperature the second fan will start working. Thus it will cause suction, so if the hot air in the chamber to outside and the temperature will get back to the target which was mentioned previously. In this way, the product will be prevented from burning. High temperature may cause the product to lose more moisture, which is not desired. Also, losing more moisture can cause losing valuable micro components in tea and change the taste too.

\section{Processing unit}

In industrial high capacity, dryers use PLC-based systems in monitoring unit. These systems are very expensive and it is not suitable for small-scale systems. Another approach to solve this problem is using low-cost controllers. The Low-cost controllers require some reliable noise filtering circuits in power supply and analog sensor units. If good noise filters are selected in monitoring circuit, the suitable and also low-cost controller will be obtained. One of these approaches is the microcontroller processor. Therefore, a microcontroller as the main processor is deployed to process sensors data and manipulates suitable behavior in drying process. The designed dryer includes several electronic units, which are digital and analog components, as shown in Fig. 1. The processor unit must be able to execute several tasks such as Reading sensors' value, Manipulate suitable control signal, Fan and heater control, Data logging, PC communication.

For sensory system managing, analog to digital converter (ADC) unit of microcontroller is used to digitize captured sensor's value. This unit provides digital value of analog sensors. After capturing samples of sensors, processing function decides suitable output signals according to defined drying period. In proposed system, Fan 1 and heater unit are controlled with pulse width modulation (PWM) approach. In this technique, when the pulse width gets longer it results to increasing output values which are fan's speed and heater temperature. Table I illustrates the ratio of PWM to the output value percentage. The PWM variable is between 0 and 1023. The average of output value is calculated by the following formula:

$$
V_{\text {out }}=\left(t_{\text {on }} /\left(t_{\text {on }}+t_{\text {off }}\right)\right) \cdot V_{\text {in }}
$$

Where $t_{\text {on }}$ is duration of pulse with logic one and $t_{\text {off }}$ is duration of pulse with zero logic.

The PWM technique allows controlling utilized devices in various output levels. This approach provides to control heater temperature smoothly. In older drying systems, heaters and fans were controlled with relay and controller sent only ON and OFF commands to relay. Also, the Fan 1 speed is controlled with PWM signal. Two separate PWM channels are used to control heater and Fan 1.

In addition, an external memory is used to record sensors value as the data logger. This memory is structured as the simple data base which has two fields, time and sensors' value. Sampling step is changeable for each types of drying process.

The other feature of this controller is capability to communicate with PC. Two applications are defined in this connection, i) reading recorded values during drying process, ii) on-line controlling. After connecting dryer to PC, data logger values will be downloaded by standard serial cable. Downloaded values are real data in drying process to be use for drawing dryer process diagrams. In addition, designed system enables to get control signals from PC. During drying process, PC receives digitized sensors value and decides provides control commands, which are fans, heater, and valves control signals.

\section{Results and Discussion}

Sufficiently wet tealeaves are fed into the dryer; in this stage, wet tea is in contact with high temperature air (around $95^{\circ} \mathrm{C}$ ) then after tealeaves start drying. In this procedure, air takes the moisture from tea thus its dry bulb temperature declines. At the same time as the dry bulb temperature of air drops tea leaves start losing there moisture content and 
there temperature increases from wet bulb temperature of air to dry bulb temperature of air. The heat utilization of the air above the trays was found when the discharging tea was at the moisture content of around $3 \%$. The number of trays in this experiment was eight. Fig. 3 indicates the relationship between moisture content of leaves and their temperature.

As shown in Fig. 3 at the first stages, the slope decreases dramatically but when it reaches to less than $10 \%$ of moisture content, it declines slightly around 3\%.It can be understood that the leaves temperature increases significantly when the leaves have lost moisture in a considerable quantity. The raise in temperature is only $10^{\circ} \mathrm{C}$ from the moisture content of $68 \%$ to less than $10 \%$ but from this point further the temperature increases from around $45^{\circ} \mathrm{C}$ to $80^{\circ} \mathrm{C}$. The reason for this matter is that at the begging of the process tea leaves get the temperature to reach to the critical moisture content so they use the heat that they receive from air to lower their moisture content, and then when they reach to the critical point the heat that they obtain from the air is used to increase their temperature.

Fig. 4 illustrates the relationship between moisture content of the leaves and the temperature of them in each tray by centigrade in different stages of drying. The capacity of the dryer is proportional to the heat of the air above the trays. Although, if the temperature is not high enough it could lead to liquor and stewing of the leaves during the drying process but very high temperature can also cause casehardening and burning of the leaves. The temperature of the air above the trays was between $50^{\circ} \mathrm{C}$ and $95^{\circ} \mathrm{C}$ so the less damage would occur on tea leaves. Moisture content of leaves dropped from $68 \%$ to under $3 \%$ at $95^{\circ} \mathrm{C}$.

Equilibrium moisture content could be found by the standard method (ISO 1980) the technique is by measuring the decrease in mass at temperature of $100^{\circ} \mathrm{C}-105^{\circ} \mathrm{C}$, the tea equilibrium with the air at above $100^{\circ} \mathrm{C}$ is determined as having zero moisture content, hence the equilibrium moisture of tea with ambient air to over $100^{\circ} \mathrm{C}$ is zero(Temple, Boxtel, 1999)

\section{Conclusion}

The batch tea dryer system based on programmable controller is presented in this paper. We designed a new dryer machine, which utilizes hot air chamber to drying several tea genres. Pulse width modulation approach is employed to control heater and fan with smooth level. The several performed experiments show that the best quality of dried tea leaves will be occurred when the chamber temperature was above $83^{\circ} \mathrm{C}$ and $99^{\circ} \mathrm{C}$. Furthermore, the exhaust temperature must be in the range of $49^{\circ} \mathrm{C}$ and $57^{\circ} \mathrm{C}$ that was depended on the entrance air temperature. And the leaves temperature increased from $30^{\circ} \mathrm{C}$ to $80^{\circ} \mathrm{C}$. The drying process took about 15 to 25 minutes depends on the thickness of the leaves, quantity, and types of the tea which are subjected to drying. In this process, the inlet air was $94^{\circ} \mathrm{C}$ and the moisture content of the leaves reached to the target of less than $3 \%$. The proposed dryer is mostly designed for laboratory scales and the obtained results were efficient for industrial layouts.

\section{References}

Buja, G. S., \& Kazmierkowski, M. P. (2004). Direct Torque Control of PWM Inverter-Fed AC Motor - A Survey. IEEE Transaction on Industrial Electronics, Vol.51, pp.744-757

Canovas, GV. Barbosa, \& Ma, L., \& Barletta, B. (1997). Food Engineering Laboratory Manual. USA: Technomic Publishing Company, pp.63-77

Crapiste, G.H., \& Rotstein, E. (1997). Design and Performance evaluation of Dryers, Handbook of Engineering, Practice, Ed.K.J Valentas, E. Rotestein, and R. P. Singh, CRC Press, Boca Raton, FL, pp.125-166

International Standard Organization. (1980).

Javanmard, M. \& Arvin, F. (2008). Tea Dryer with Programmable Controller, Registration Office of Industrial Ownership, Iranian Patent No.48839

Jayaraman, K.S., \& Gupta, DK Das. (1995). Drying of Fruits and Vegtable, Handbook of Industrial Drying, Vol.1, $2^{\text {nd }}$ Edition, New York: Marcel Dekker, pp.643-690

Mujumdar, AS, \& Menon, AS. (1995). Drying of Solids: Principles Classification, And Selection of Dryers, Handbook of Industrial drying, Vol. 1, $2^{\text {nd }}$ Edition, New York, Marcel Dekker, pp.1-39

Temple, S. J., \& Boxtel, A.J.B. (2001). Automatic Endpoint Determination for Batch Tea Dryer. Journal of Agriculture Engineering, 78(1), pp.51-56

Temple, S.J., \& Boxtel, A.J.B. (2000). A comparison of Dryer types used for tea drying. Journal of Agriculture Engineering, 77(4), pp.401-407

Temple, S.J., \& Boxtel, A.J.B. (1999). Equilibrium Moisture Content of Tea. Journal of Agriculture Engineering, 74, pp.83-89

Valentine, R. (1998). Motor Control Electronics Handbook. McGraw Hill. 
Table 1. The PWM variable value and output percentage

\begin{tabular}{ll}
\hline \hline PWM Register Value & Output Percentage \\
\hline 0 & $0 \%$ \\
256 & $25 \%$ \\
512 & $50 \%$ \\
768 & $75 \%$ \\
1023 & $100 \%$ \\
\hline \hline
\end{tabular}

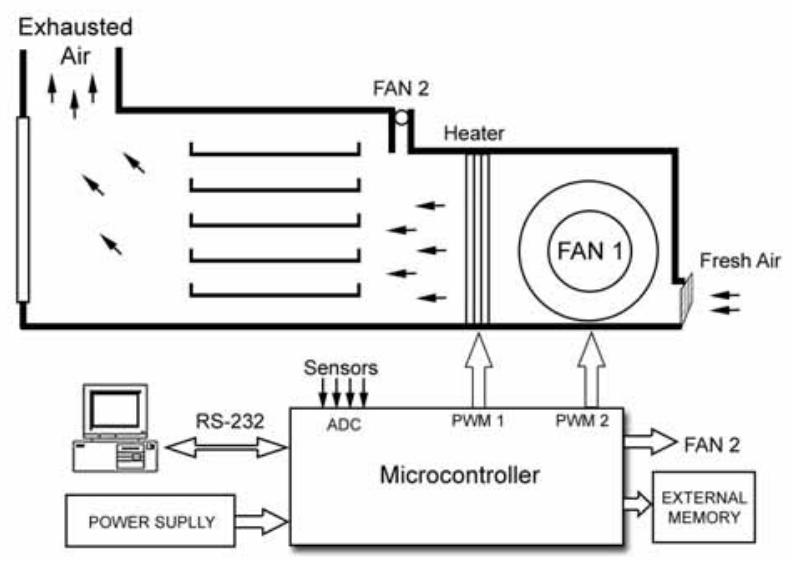

Figure 1. Schematic of designed tea dryer
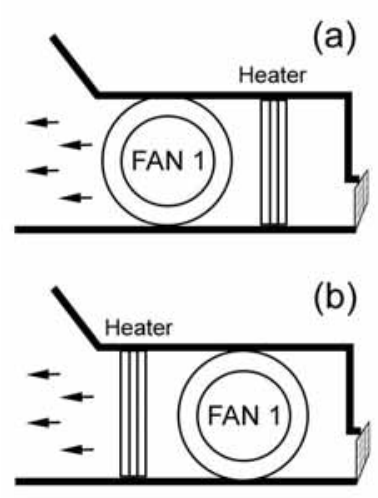

Figure 2. (a) Heater is before the fan, (b) heater is after fan 


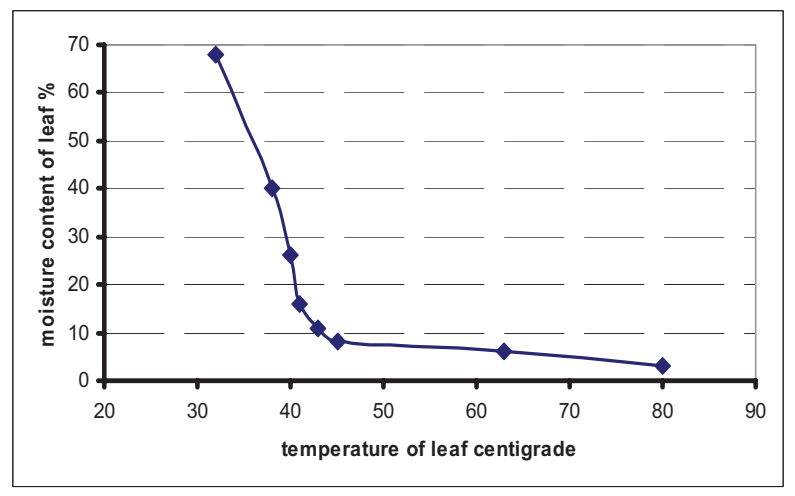

Figure 3. Temperature of leaf versus moisture content of leaves observed in drying process

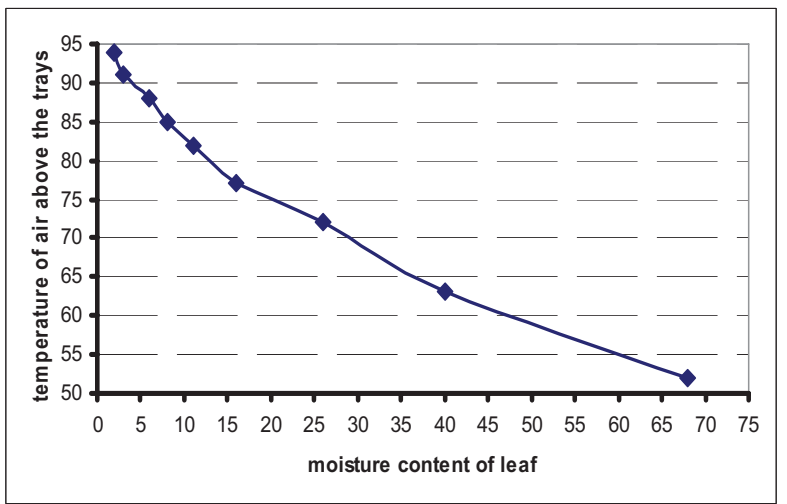

Figure 4. Temperature ratio of air above the trays versus moisture content of leaves observed in drying process 